\section{B A Institute of \\ YK Business Administration \\ 六下 \\ Karachi \\ Leadership and Ideas for Tomorrow}

Business Review

Volume 9 Issue 2 July-December 2014

$7-1-2014$

\title{
Growth of business schools on social media: A comparative analysis with focus on IBA Karachi
}

\author{
Erum Hafeez Aslam \\ Institute of Business Administration, Pakistan
}

Follow this and additional works at: https://ir.iba.edu.pk/businessreview

Part of the Nonprofit Administration and Management Commons, and the Technology and Innovation Commons

(c) (1)

This work is licensed under a Creative Commons Attribution 4.0 International License.

\section{Recommended Citation}

Aslam, E. H. (2014). Growth of business schools on social media: A comparative analysis with focus on IBA Karachi. Business Review, 9(2), 158-175. Retrieved from https://doi.org/10.54784/1990-6587.1278

This article is brought to you by iRepository for open access under the Creative Commons Attribution 4.0 License and is available at https://ir.iba.edu.pk/businessreview/vol9/iss2/12. For more information, please contact irepository@iba.edu.pk. 
https://ir.iba.edu.pk/businessreview/vol9/iss2/12

DOI: https://doi.org/10.54784/1990-6587.1278

Business Review - Volume 9 Number 2

July - December 2014

CASE STUDY

\title{
GROWTH OF BUSINESS SCHOOLS ON SOCIAL MEDIA A COMPARATIVE ANALYSIS WITH FOCUS ON IBA KARACHI
}

\author{
Erum Hafeez Aslam \\ Institute of Business Administration, Pakistan
}

\begin{abstract}
When the Institute of Business Administration Karachi established a presence on various social media platforms in 2009, its audience and followers grew dramatically. Face book, Twitter, YouTube and LinkedIn all proved to be useful tools to disseminate information for its target audience including prospective and current students, faculty, staff, alumni, parents and industry.
\end{abstract}

By 2012, however, social media activity became somewhat stagnant, as it was observed that content on various interfaces, although informative, lacked engagement and interaction with the audience. After several months of close monitoring, a number of issues were identified; for example, content only consisted of program and event announcements; slow response time to queries; lack of posts that would attract foreign audiences; and immense need to monitor the pages for removal of garbage material. It was then decided that a comprehensive Social Media Strategy should be developed with the primary goal of increasing the visibility of IBA on all its current social media platforms in order to attract more talented students and high caliber faculty.

IBA's Social Media Strategy is based on four key design principles viz., Listen, Engage, Interact and Inform its audience, with content being the most important driver for the success of Social Media. IBA's Social media metrics indicate that the strategy has been successful to an extent, with the number of 'Likes' on the Face book page and posted content showing a rise, along with an increase in the number of comments, reviews, queries, Facebook visits, YouTube views, followers on Twitter, re-tweets and Talking About.

However, comparison with other leading business schools in Pakistan and overseas indicates that IBA still lags behind. One of the strengths of IBA is its 27 highly active student societies and numerous academic departments, which, if properly engaged, could provide a constant stream of high quality, student generated content.

Keywords: ICT Social Networking, Digital Media, Business Schools, Content, Target Audience, Strategy

\section{Introduction}

It was early Monday morning when Ashar was sitting in his office at the second floor of IBA's new Center for Entrepreneurial Development (CED)building. He had just 
arrived and was sifting through his cluttered email inbox when he noticed an urgent email from the Senior Manager Information Systems. His first inclination was to leave it for later, but as Manager Communications and Public Affairs, he knew that would be irresponsible. Reluctantly, he opened the email and read through the urgent message calling all members of top management and Program Heads for an emergency meeting. He wanted to address the issue of their online social media presence, which although was enjoying a fan-base of an impressive (at the time) 26,000 members, was in all honesty, pretty dormant. Ashar knew he would soon be getting an anxious call from the Dean and Director to look further into the matter. And sure enough, the phone rang within moments with instructions to devise a pragmatic social media strategy and action plan by the next quarter to effectively utilize IBA's social media platforms for student engagement, corporate communication and marketing campaigns. Ashar attended the meeting and soon a Social Media Committee was formed for the purpose.

\section{Background}

\section{Institution of Business Administration (IBA) Karachi:}

IBA is one of Pakistan's premier business schools, which has been producing top quality graduates since 1955. IBA is perhaps the single most influential institute in terms of its contribution towards the economic development of Pakistan. The IBA was set up in 1955 in collaboration with the Wharton School of the University of Pennsylvania. The school was initially a graduate school for business studies and the first business school outside of North America. From a business school within the University of Karachi, IBA's status was elevated to that of an independent, degree-granting institution in Pakistan in 1994 when it received a charter from the Sindh government (Program Announcement, 2012-13).

Since its establishment, IBA has been known for its merit, discipline and quality of students. It has a 58-year old heritage that has produced a large network of around 10,000 alumni, now working as top entrepreneurs, key decision-makers, strategic planners and opinion leaders in organizations, both in Pakistan and abroad (IBA Website, Dec. 2013).

IBA enjoys a reputation of being innovative and ahead of the game. More recently, IBA has set new strategic directions for itself, and is now progressing rapidly along the dimensions of program, faculty and infrastructure development.

\section{IBA's Marketing History:}

IBA's marketing strategies have undergone significant transformations in recent years. If one only considers the advertisements that used to be published in leading national Urdu and English newspapers, the evolution over the past six years is evident.

Prior to the age of digital media, when IBA relied heavily on print ads alone, it can be seen that traditional ads used to be extremely text heavy, lacked pictorial content and provided readers with all relevant information, such as eligibility criteria for the various programs on offer, the admissions process, financial assistance details, important dates, contact Information and other data. However, even as recently as 2009 , it can still be observed that IBA followed a very old-fashioned style of one way communication, where IBA was the provider of all relevant details and the audiences were the consumers of information.

This mindset was also prevalent when IBA started to develop a presence on various social networking sites such as Facebook and Twitter. IBA would push out information on a 
regular basis, announcing admissions, vacancies, convocations, tender notices and other happenings. However, with competition steadily increasing from other local business schools and digital media - especially social media platforms - gaining a stronger footing in the minds and social lives of the target audience comprising mainly of students, IBA found itself in need of better ways to reach out to its market.

Hence, IBA started to restructure its Communications Department and develop a Communication Strategy. Following the $4 \mathrm{R}$ strategy - revise, reform, reinvent and reinvigorate, IBA's Communication and Public Affairs Department started to implement a number of changes. Firstly, in terms of print ads, IBA initiated to revamp its designs, having engaged various ad agencies through a pre-qualification process. On campus photo shoots allowed the incorporation of photos of IBA's facilities and various aspects of students' life across campus, allowing for a more relevant human element and youth-friendly message. Ads started being published with less text and appear more reader-friendly. By directing readers towards the website for more information, students are exposed to a lot more than can be printed in newspaper ads. For example, by visiting the IBA website, prospective students can access a host of information through IBA's online newsletters; learn more about faculty members, read more about the programs on offer, and much more(The Current, 2011).

IBA's social media strategy has also been upgraded to include more than just oneway communication. If students are to visit IBA's Facebook pages now, they will find up-todate information regarding student activities and achievements, alumni updates, faculty developments, various academic departments, public service announcements, and all other IBA-related information through photos, videos and status updates - all in semi-formal, accessible English for diverse audiences. The Facebook page provides a platform for realtime discussion and students can post queries and expect prompt responses from the concerned.

However, in terms of marketing, IBA still has a long way to go. As the following case study will highlight, in comparison to its regional competitors, IBA has yet to develop a more streamlined communication strategy and develop a stronger, more focused presence on the new media.

\section{Social media in Pakistan}

Social Media Technology (SMT), a relatively new phenomenon in Pakistan, has gained immense popularity in a short span of time while transforming the ways in which the youth of Pakistan communicate, interact and socialize. According to Evan (2013), "With an estimated mobile penetration of 70 percent and internet penetration of 16 percent by mid2013; including more than 125 million mobile subscribers - a figure that ranked Pakistan 5th largest mobile phone market in Asia (Teller, 2013); more than 30 million Pakistani Netizens (Sanou, 2011); and around 8 million Facebook users, seventy percent of whom are below the age of 30 (World Economic Forum, 2012), one can only imagine the potential of this rapidly growing media on the youth and thereby in the social transformation of the country.

Social bakers (2013) estimated, "Face book attracts the majority of native netizens whereas other social media interfaces are also growing gradually. The population of native netizens is growing at a rapid pace because of its fast-paced, time saving, convenient and cost effective nature." Twitter is mostly used for news and updates. Linkedin is a preferred platform for professional linkages and networking. Google is becoming increasingly popular as well. Blogs are also gaining public attention and have a large network of bloggers. Pakistan 
has a lot of potential in e-commerce business and travel websites. Currently, online shopping has seen an upward trend and Facebook pages are a main source of inspiration for retail businesses(Social Media Trends in Pakistan, 2013).

\section{Literature Review}

A thorough research has been conducted by various researchers to examine the existing findings about the impact of SMT within higher education institutes, especially about different types of SMT being used, extent of its usage, its social implications and its effectiveness in students' and alumni connections.

"Most of the available studies in this area has been based on four- year colleges and universities, where the common trend of using social media as a communication tool for individual entities prevails, with a lack of institutional commitment towards it being integrated into a larger system" (Charles, Davis, 2012).

The huge success of social media in the field of communication is reflected by research findings which reveal that $96 \%$ of the millennial population is using at least one social network (National School Board Association, 2011). Moreover, Facebook membership reached 200 million marks within less than a year of its launch. Social media has opened up new avenues for organizations and manufacturers to make their presences felt and communicate with their target market. Social media also allows them to reach out to the niche audience and adapt their messages accordingly. Many companies and service providers are availing this opportunity to strengthen their marketing and promotion efforts.

Colleges and universities are also adopting the same media to extend its reach and impact. There is a great potential for social media with reference to academic institutes; however, very limited research has been conducted on the issue of its real and potential usage and effectiveness. Whether, social media networks prove to be an appropriate channel of communication and marketing for academic institutions in developing countries like Pakistan is yet unclear.

It is of significant importance that we start studying how higher educational institutions incorporate the use of social media technology in various functions like learning, student engagement, marketing and recruiting, and how are they employing it to connect with their students and facilitate them effectively.

The use of blogs, Facebook, Twitter and other social media interfaces like Flickr and YouTube is also recommended by Dr Rachel based on survey results of 148 colleges and universities (Rachel, 2012).

According to a study conducted by the University of Massachusetts for Marketing Research (2012), usage of social media by the admission offices have increased over the years, from sixty-one percent of the respondents, using at least one form of social media in 2007 to ninety-five percent students by 2009.

A survey carried out by National School Boards Association (2011) further confirms the high usage of social media by students and reports that sixty percent of those on social networks talk about topics related to education. Moreover, they express themselves through social media tools, generating and passing online content. 
Although the presence of students on social media sites is high, a small percentage of students employ SMT for searching colleges when deciding to apply (Social Media for Higher Education, May 2012).

\section{Institute of Business Administration (IBA)Karachi at Social Media}

Case Problems: The Institute of Business Administration Karachi (IBA) adopted Social Media by developing its own social hub, and established a presence on social media platforms such as Twitter, LinkedIn, YouTube and Facebook in 2009. "IBA has crossed the learning curve in this area, and needs a Social Media Strategy to formalize existing practices and provide guidelines for the future"(Social Media Strategy Paper, 2012).

IBA had maintained a presence on various social media websites for over three years by 2012. However, it was neither duly active nor as vibrant as required. Most of the IBA social media pages were dormant, centralized and boring.

As a result, IBA had failed to listen, engage, educate and entertain its various audiences. Most of the time, IBA's social media presence was limited to static notices linked to PDFs and posts on the IBA website. The primary objective seemed to repost web information through another channel mostly irrespective of the feedback from the audience.

\section{Case Problems/Questions}

1. What should be done in terms of an effective strategy and what could be the standard operating procedures for producing and posting relevant content?

2. Who should be involved at which level?

3. How can it be put into practice? Where shall it start and what should be the timeline?

4. How can IBA's Social Media presence be made more lively, interactive, engaging, entertaining and informative for current and aspired audiences for advertising, marketing and educational purposes?

5. Why is it important to use social media for official and institutional communication and engagement?

\section{Why was there a need for a Social Media Strategy?}

IBA jumped on the Social Media bandwagon in 2009, when it developed its own social hub by establishing its presence on social platforms such as Twitter, LinkedIn, YouTube and Facebook. IBA has now crossed the learning curve in this area, and therefore needs a Social Media Strategy to formalize existing practices and provide guidelines for the future.

IBA's Social Media Strategy is based on four key design principles. These principles will enable IBA to Listen, Engage, Interact and inform prospective students and other stakeholders such as faculty, staff, current students, alumni and society at large.

IBA's Social Media Strategy is intended to increase IBA's visibility on social platforms and thereby attracting more talented students and faculty. Secondary goals include improving internal communications, and use of social media in the classroom for delivering quality education.

\section{Target Audience:}


The primary target audience is the technology-savvy youth and prospective students. Other intended audiences of IBA's Social Media include current students, faculty, staff, alumni, industry and society at large.

\section{Content:}

Content is perhaps the single most important driver for the success of Social Media. IBA needs to produce a constant stream of high quality content for its social channels. The opportunities for producing content already exist at IBA. There are 27 student societies that conduct various events and activities on a regular basis both at local and national levels. Other important events include the Director's speeches, Guest Speaker visits, Convocations, Conferences and Reunions.

IBA's Social Media Strategy recommends video recording all important public events and activities, especially the Director's speeches at Orientation sessions, Mega Events organized by student societies, Distinguished Guest visits and other such events.

\section{Channels:}

IBA would focus on Face book, LinkedIn, YouTube and Twitter for information dissemination as well as for both internal and external interactions.

\section{Methodology}

\section{Measurement and Assessment:}

Various Social Media metrics such as number of comments, reviews, queries, clicks, clikthroughs, Facebook visits, YouTube views, re-tweets, Twitter followers, Facebook 'Likes', Talking About, as well as traditional measures such as in-house surveys and focus groups will be used to assess the success of IBA's Social Media Strategy.

\section{How would Social Media Technology (SMT) be beneficial to enhancing the image of IBA?}

It is estimated that more than 30 million Pakistani NETIZENS are online today and the population is growing at a rapid pace. According to Kemp (2013), "social media is more popular among the local male population (i.e.75\%) than female population (i.e. $25 \%$ )".These statistics, however, are debatable since many female users create accounts on social media as males in order to hide their identity for privacy reasons. The demographical study of the net users further reveals that around $70 \%$ of them are below the age of 24 .

Furthermore, an international survey titled Social Media for Education (2012) further reflects that " $70 \%$ of the students suggest that colleges should have a presence on social networks; $50 \%$ want to be contacted directly through a social network and around $81 \%$ access the net wirelessly."

Considering IBA's target audience of 18- to 24- year-old college students, the younger high school crowd, alumni, parents of students, potential donors, faculty, staff and other stake holders (which are just a 'tweet' or a 'like' away), there is no choice but to integrate social media platforms into IBA's overall marketing and communications plans.

\section{IBA's status on its various Social Media Platforms}

A baseline study of various Social Media interfaces such as Facebook, Twitter and YouTube from May 2012 to July 2012 and then to March 2013 was conducted to evaluate the 
popularity and activity of IBA on these social media websites to gauge its progress over a period 11 months.

\section{IBA on Twitter}

According to the comparative analysis, IBA's activity on Twitter showed a slight increase with the number of tweets increasing from 122 in May 2012 to 195 in July 2012. After the introduction and implementation of the Social Media Strategy, this number more than tripled to 682 tweets by March 2013, indicating progress in IBA's Twitter activity.

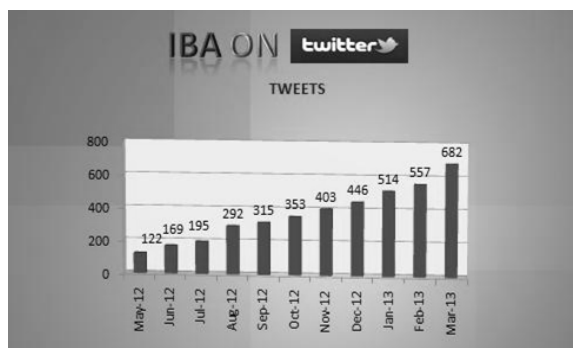

In terms of the number of followers on IBA's Twitter page, the figure more than doubled from 34 in May 2012 to 76 in July 2012. However, after the Social Media Strategy was put into effect, the number of followers reached 480, showing a $600 \%$ increase, in March 2013.

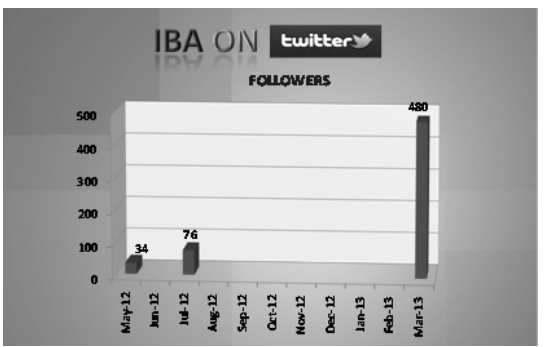

\section{IBA on Facebook}

An evaluation of IBA's Social Media activity also included a study of the number of 'likes' and 'talking about' on its Facebook page. According to the baseline study, the number of 'likes' showed a negligible rise from 31,033 to 32,484 between May 2012 and July 2012. However, in March 2013, the figure showed a significant climb to above 55,000 'likes', indicating an average increase of over 2,000 'likes' per month.

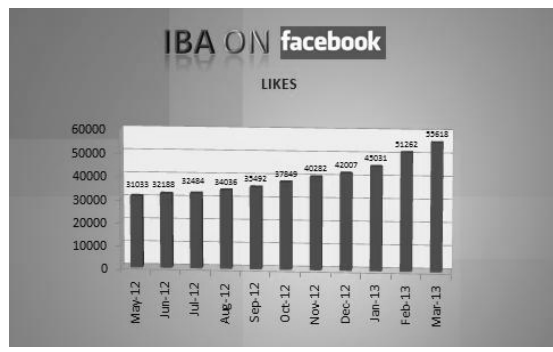


Another key measurement metric on Facebook is 'talking about', which signifies the number of Facebook users talking about the page or its various content. In 2012, the figure showed a decrease from 610 in May 2012 to 448 in July 2012, however, by March 2013, the number tripled to 1,305 after the Social Media Strategy was put into practice. It was in fact February 2013 that exhibited remarkable increase with 2951 talking about probably because of the content variety and frequency of interaction on IBA FB page.

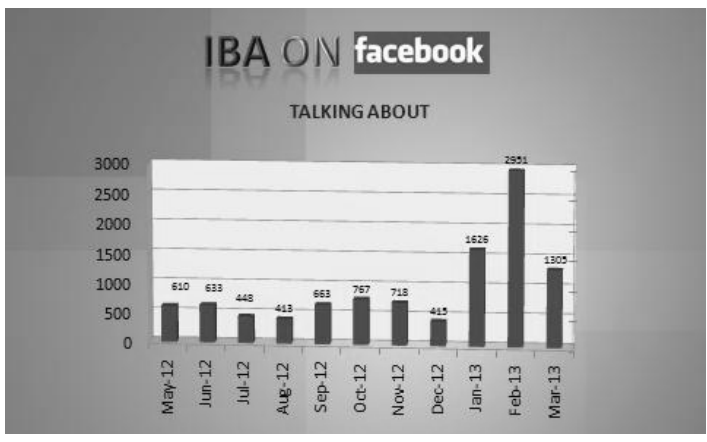

\section{IBA on YouTube}

YouTube, an important social media video website, was evaluated for the nature of content and number of videos on the IBA YouTube page from May 2012 to July 2012. It was noted that there was slight improvement in the number, quality and variety of videos uploaded on IBA's YouTube which increased from 28 official videos in May 2012- mostly comprising of Dr. Ishrat' $s$ interviews (all recordings of Geo TV interviews) to 35 videos showcasing various events and activities of students such as OmoreAdwar and IMC introductory activities.

It is also worth noting that YouTube has been banned in Pakistan since September, 2012 thus limiting IBA's activity and presence on YouTube. Also, as a result, pertinent data about the ongoing progress has been difficult to attain after that.

\section{IBA in comparison to Stanford University, Lahore University of Management Sciences (LUMS) and Karachi School for Business and Leadership (KSBL)}

A baseline study of various Social Media interfaces such as Face book, Twitter and YouTube from July 2012 to March 2013 was conducted to compare the popularity and activity of social media pages of various universities, such as that of Stanford University, LUMS and KSBL in comparison to IBA Karachi.

The purpose of comparing IBA Karachi to LUMS is because LUMS is seen as a natural competitor to IBA; much younger than IBA, LUMS has been compared to IBA in numerous aspects and rankings. KSBL is the emerging business school in Karachi. In its short history, KSBL is rapidly gaining great popularity on Social Media websites. Also, KSBL's Social Media activity is being handled by an IBA graduate. Stanford University is one of the top-ranking business schools in the world and its Social Media activity and achievements are being used as an international benchmark for comparison. 


\section{IBA on Twitter}

In July 2012, in comparison to IBA's 195 tweets, LUMS had tweeted 522 times and KSBL 165 times, while Stanford University led with a total of 5,596 tweets. In March 2013, however, a shift in scenario shows IBA's Twitter activity to have more than tripled with 682 tweets, LUMS's activity to have less than doubled with just under a total of 1,000 tweets and KSBL's activity doubling to a total of 346 tweets. Stanford University showed only slight but steady growth in its Twitter activity with a total of 6,708 tweets - an increase of just over 1,000 tweets in the same time period.

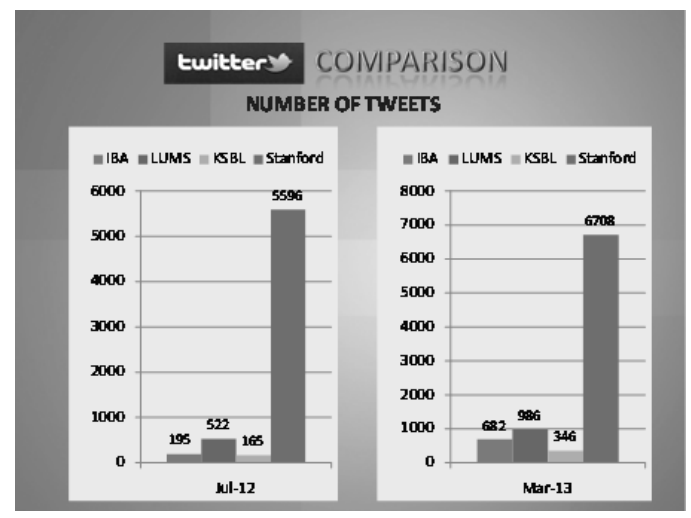

Another crucial measurement metric is number of followers. According to the baseline study, in July 2012, IBA had just 76 followers, while KSBL had 100, LUMS had 798 and Stanford University had 78,935 followers. By March 2013, while the number of followers increased six times for IBA, with a total of 480, growth was comparatively slower for the other universities: though still ahead of IBA, LUMS's followers only doubled in number to 1,755 ; KSBL's followers only increased by a handful number of 175; and the followers of Stanford University rose to a total of $111,369$.

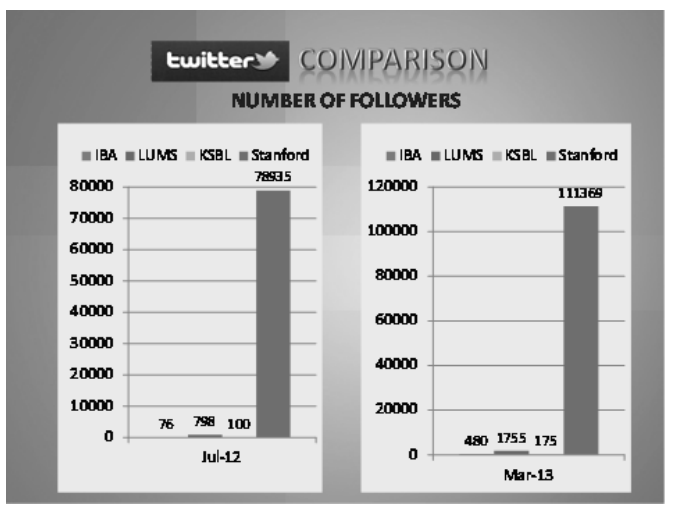




\section{IBA on Facebook}

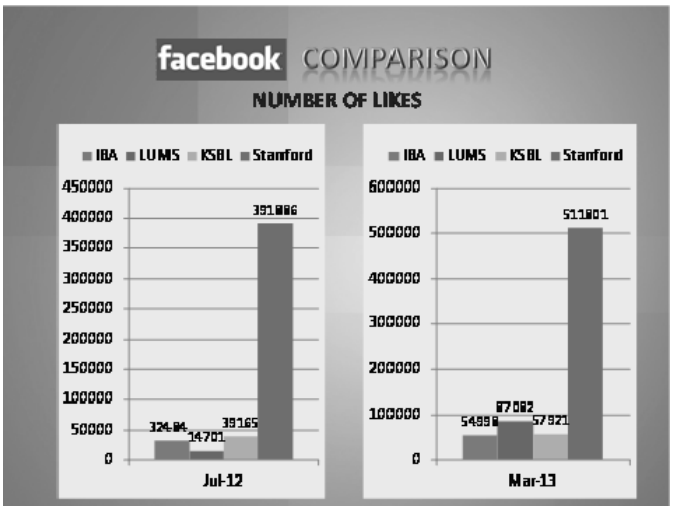

In July 2012, the number of 'likes' on IBA's Facebook page stood at 32,484 in contrast to that of 14,701 for LUMS, 39,165 for KSBL and 391,886 for Stanford University.

By March 2013, however, IBA's Facebook page saw a rise in the number of 'likes' to 54,998. LUMS witnessed a significant six-fold increase to 87,082 'likes', while KSBL - although still ahead of IBA - showed similar progress to that of IBA, with the total number of 'likes' at 57,921. Stanford University stood at 511,801 'likes', which, although the highest in this category, indicates only a steady rise.

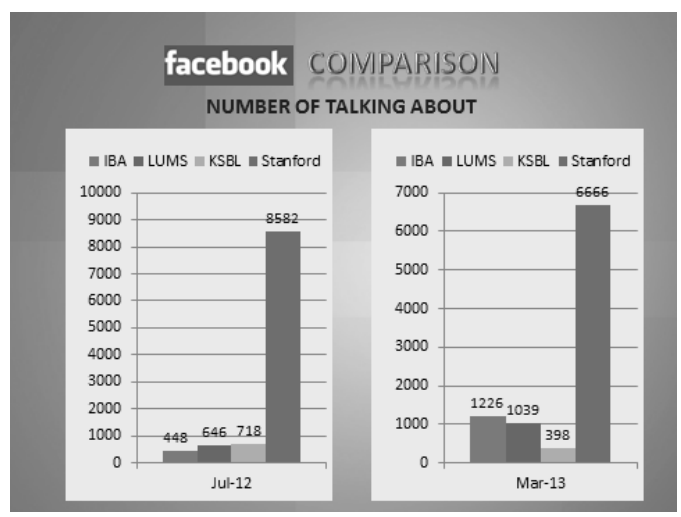

In July 2012, it was observed that most of the time untailored information was being uploaded about events and programs at IBA on Facebook, which is perhaps one of the reasons for its unpopularity among the young audience, indicated by the 'talking about' figure standing at 448. By March 2013, IBA's Facebook page showed a significant three-fold increase, outnumbering the figure for LUMS; while KSBL showed a decline to half of its initial figure in July 2012. Although Stanford University leads this category as well, its figure also shows a decline in March 2013, from its initial figure in July 2012.

\section{IBA on Youtube}

YouTube was evaluated for the nature of content and number of videos in comparison to that of Lahore University of Management Sciences (LUMS) and Karachi 
School for Business and Leadership(KSBL) and Stanford University in the months of July 2012 and March-April 2013.

Results showed that IBA had uploaded 28 videos and while LUMS and KSBL had lesser number of videos i.e. 26 and 14 respectively, their content was more targeted and needbased. Stanford University, on the other hand, was measured as a benchmark with around 1, 561 videos uploaded of diverse nature ranging from videos of students' activities to faculty lectures on variety of topics.

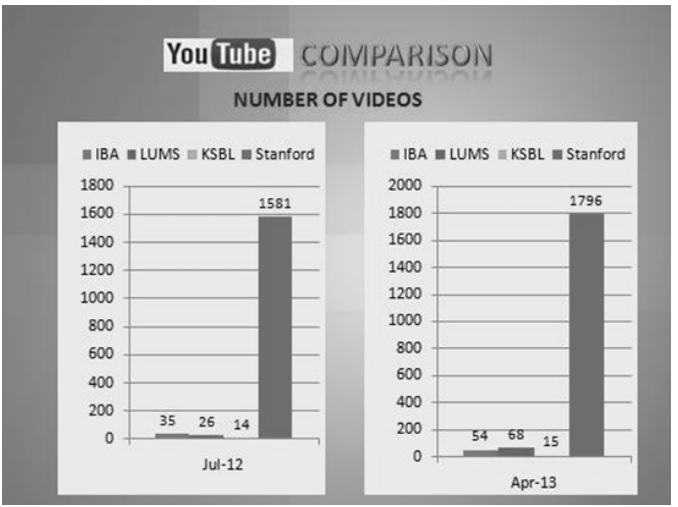

\section{Social Media Activities in other native leading Universities in Pakistan}

In order to learn how other native leading universities are doing in the area of Social Media Marketing, we did a small survey and talked to the representatives of a couple of universities.

It is discovered that the Lahore University of Management Sciences (LUMs) maintains a separate social media team headed by a Marketing Manager, who looks after the content development and monitoring of its various social media platforms. According to an official in the Marketing Department, "The LUMS team plans to manage a Blogger outreach program and build an active brand ambassador network for the University. The department ensures active entries on various video platforms such as Vimeo, and Youtube as well as Twitter and Linkedin through which it actively promotes its Alumni achievements.

Karachi School of Business and Leadership (KSBL) likewise seemed to realise the importance of social media much earlier and started using the platform since the very beginning. Digital history reveals that KSBL's Facebook page was launched in 2008 and since then the institute has managed it effectively with regular posts and real time responses to public queries and messages. However, most of the posts and updates on KSBL facebook page are primarily announcements related to seminars and lecture arranged at the university. It is found that the Students' activities are rarely highlighted on the official Facebook page. Besides, KSBL has also maintained an account on Vimeo where videos are frequently uploaded related to students and faculty activities. One can also witness KSBL's presence on Linkedin with large network and discussion groups.

When we talked to Mr Sibtain Naqvi, the Head of Media \& External Relations at the recently established Habib University, he explained the institute's digital marketing initiatives in these words, "Social media is an increasingly critical tool that helps us in reaching out to the younger audience. School students are very much in touch with Facebook and other 
online portals and it is the medium of choice for entertainment, information, connectivity and communication. We at Habib University are fully cognizant of this reality and make sure we address the engaged audience in a manner they are comfortable with and through a medium they are used to. Our successful social media campaigns and the increased reach of our message is proof of that."

\section{Factors to consider for reviving IBA's Social Media Technology}

IBA already has a Facebook page, Twitter account and YouTube existence. What IBA needs is to promote and improve its presence on these platforms. It is believed that content is one major and single source that can play a key role in improving the presence of an institution on the social media. Lots of data has been posted on IBA Facebook but it needs to be tailored. Various IBA departments also have lots of information that needs to be tapped into and it is believed that the Faculty of Computer Science, ICT, Communications and Program Offices can play a pivotal role in this regard.

Moreover, there is a need of Social Media Strategy to ensure sustained guidance, maintenance of content quality and quantity, introduction of SOPs and Standardized templates as well as sustainability of the initiatives. Social Media Committee is also needed to be formed to extend experienced and technical expertise, coordination and ownership and clarity about objectives.

\section{Roles and Responsibilities}

The responsibility of producing content for social media will be distributed among the 21 service units, with lead being taken by the Program Offices, and the Communications Department while MIS Department will be responsible for the technical support and content monitoring. It was proposed that each Program Director will spend an hour or two live on Facebook each month answering queries in real time. Update Frequency:

$\begin{array}{ll}\text { Facebook Page: } & \text { Twice Daily } \\ \text { Twitter: } & \text { Six times Daily plus as and when required } \\ \text { YouTube: } & \text { Weekly } \\ \text { LinkedIn: } & \text { Monthly }\end{array}$

Social Media metrics to be used to gauge progress: number of comments, reviews, queries, clicks, clikthroughs, Facebook visits, YouTube views, re-tweets, Twitter followers, Facebook 'likes', Talking About, as well as traditional measures will be used to assess the success of IBA’s Social Media Strategy.

\section{Potential Challenges:}

25 Social Media is a time consuming job.

25 Without assigning the job any specific department, it might lack ownership.

Es Employees have multiple tasks thus might be reluctant to take it as their responsibility.

2 Weak in-house communication and coordination are some of the major obstacles.

2s No specialized, technical skills can be considered a handicap in this regard. 


\section{Recommendations:}

The individual's contributions to IBA's Social Media pages should be considered at the time of performance evaluation.

\section{SOPs for Social Media Content:}

25 All departments to share content for social media as part of their event report

2s Public events to be taped and aired on social media in real time (Without waiting for official approvals)

2s Academic related pages to be 'liked' through official page to increase traffic

25 Consistent monitoring of competitors and efficient modification of IBA social media pages to be ensured pertaining to changing times

2) Avoid uploading or giving links of PDF files and print ads

es Code of Conduct and SOPs shall be introduced to ensure effective functioning

Es Legal Protection should be provided for comments on social media to avoid any legal charges

2s Regular Live sessions and Live Tweeting to be promoted by encouraging various support departments, program directors, alumni and society managers to participate actively

2 At least two tweets to go out per day as per policy

\section{Steps in the experimental launch:}

2s Formulate a Social Media Team/Committee

2) Develop a Social Media Strategy through coordination

2s Coordination with all relevant departments and dissemination of new social media policy

2s Decentralization through designating tasks to representative of various departments while data should be monitored and filtered by the central social media committee

2s Improve and activate the current IBA Facebook page and link it to YouTube, LinkedIn, Twitter and other relevant pages

2s Bimonthly meeting to ensure check and balance and maintain pace of the progress on social media

2s Further maintenance of Weblog is suggested for Program Office and HOD are required to take the responsibility of providing relevant info for social media timely.

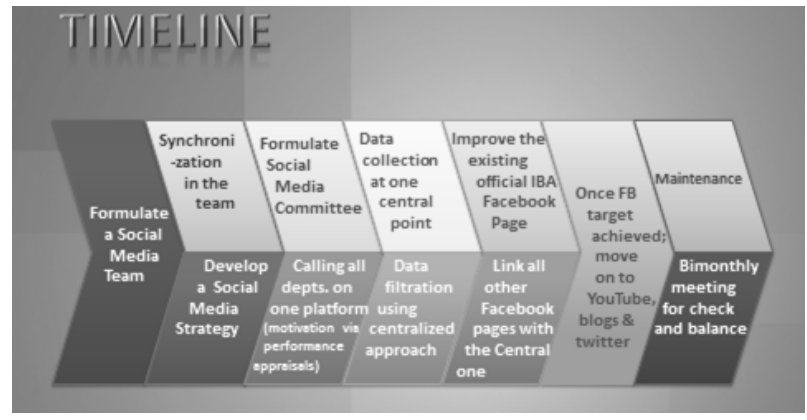




\section{Conclusion}

The formation of the Social Media Committee and the development of the Social Media Strategy have shown significant improvement. For example, as per the guidelines in the Strategy, the content now includes not just program and event announcements, but also photos and videos of Director's speeches, guest speaker visits, conferences, reunions and other Student Society events. Although currently limited, content also includes interesting newspaper and magazine articles, quotes and interesting status updates.

Considering the yardstick set above, IBA has been partially able to achieve its set goals: Qualitatively, activity shows an evident increase on IBA's Face book and Twitter pages. The quality of queries and posts has also shown marked improvement.

Quantitatively, social media metrics indicate that the strategy has been successful, but only to an extent. IBA's Facebook page shows significant growth in the number of 'likes' (an average of approximately 2,000 'likes' per month) and 'talking about' (which has tripled) since content other than news and program announcements have been uploaded, as per the Social Media Strategy. Statistics also indicate steady progress in the number of comments, reviews, queries, and Facebook visits. Moreover, the number of tweets and followers has also dramatically risen in last seven months: For example, following the strategy, an increase in the number of tweets has shown an increase in the number of followers from just a handful to around 500 followers. Due to the ban on YouTube, activity has been limited; however, statistics for July 2012 show that there were around 35 videos on IBA page. Comparisons with Lahore University of Management Sciences (LUMS) and Karachi School of Business Leadership (KSBL) indicate that IBA still lags behind on Social Media activity even after the introduction and implementation of the Social Media strategy. This could be due to the nature of the content, which still lacks audience interaction and engagement, requires tailoring and guidance regarding quantity and quality of information, and SOPs and standardized templates need to be developed.

Social media is time-consuming and as faculty members are busy with a number of other responsibilities, they may be reluctant to engage. Also, without central control there is a lack of ownership. Furthermore, lack of technical skills would be considered a handicap. Finally, weak in-house communication and coordination is an obstacle.

\section{Further Suggestions:}

Engaging Students and Societies: One of the strengths of IBA is its 27 highly active student societies, which, if properly engaged, could provide a constant stream of high quality, student generated content, such as photos, videos, Twitter updates and even blogs.

Decentralization: The various academic departments of IBA have ample information, are active and organize various activities and events throughout the academic year. Engaging them would provide news and information on latest academic developments occurring at IBA as well. They could be given the authority to post latest updates and other relevant departmental information.

Response Level and Expert Engagement: providing prompt, succinct and official replies to queries; introducing interactive activities/competitions and polls to enhance engagement with the audience; and developing a central authority, well-versed in social media regulations, to monitor comments, contribute posts and check for violation of policies. 
https://ir.iba.edu.pk/businessreview/vol9/iss2/12

DOI: https://doi.org/10.54784/1990-6587.1278

Business Review - Volume 9 Number 2

July - December 2014

Other Suggestions:

1. Allowing content to be entertaining, engaging even controversial

2. Allowing openness, flexibility, and a Democratic approach

3. Ownership and engagement at higher level

4. Expert engagement

5. Mainstream Paid Marketing \& Advertising

In terms of content, include having general content on 'slow' days, such as: posts/questions relevant to the top news stories of the day (current affairs, politics, national sports, educational developments and other relevant topics); Seasonal posts (such as staying safe in the summer) and taking advantage of cultural or religious holidays. Other types of content could include information provided by faculty members who could be encouraged to share interesting aspects of their research or the research of their final year students to help market the academic achievements of the Institute. Interesting facts from the course of history of IBA could also be shared with old photographs to engage alumni. To put this into effect, a group of student volunteers could be briefed and trained to take ownership and responsibility for researching and developing content and filtering through content that is received for posting. For relevant information gathering from student societies, an elected Communications Officer for each society could be held responsible for disseminating event announcements, photos, videos and other content.

\section{Refrences}

Association, N. S. (2007).

http://www.masternewmedia.org/learning_educational_technologies/socialnetworking/social-networking-in-education-survey-on-new-generations-social-creative-andinterconnected-lifestyles-NSBA-20071109.htm\#ixzz25UBFVz8s. Retrieved from http://www.masternewmedia.org:

http://www.masternewmedia.org/learning_educational_technologies/socialnetworking/social-networking-in-education-survey-on-new-generations-social-creative-andinterconnected-lifestyles-NSBA-20071109.htm\#ixzz25UBFVz8s

Davis, C. (2012). Social Media in Higher Education: A literature review and research directions. The Center for the Study of Higher Education, The University of Arizona and Claremont Graduate University .

Department, C. (2011, December). Annual Issue. The Current , 5, p. 12.

Facebook Statistics by Country. (2012, July 18). Retrieved from http://www.socialbakers.com/facebookstatistics.

Gitelman, L. (2008). Always Already New; Media, History and the Data of Culture . London, England: Massachusetts Institute of Technology.

http://www.itu.int/net/pressoffice/backgrounders/general/pdf/5.pdf. (n.d.). Retrieved from http://www.itu.int/net/pressoffice/backgrounders/general/pdf/5.pdf 
IBA Karachi, R. O. (2012-2013). Program Announcement. Karachi: Institute of Business Administration, Karachi, Pakistan.

IBA Social Media Strategy Paper and Action Plan . (2012). Retrieved from www.iba.edu.pk.

IBA Website. (2013, June 30). Retrieved June 2013, from www.iba.edu.pk: www.iba.edu.pk

Internet Population in South Asia. (n.d.). Retrieved from wearesocial.net: http://wearesocial.net/blog/2011/12/social-digital-mobile-south-asia/?utm_

J., R. (2011). Increasing importance of social media in education Hong Kong. Polytechnic University.

Karachi, I. (2012-2013). Institute of Business Administration.

Kemp, S. (2011-2012). Social, Digital and Mobile in South Asia. Retrieved from http://www.wearesocial.net/blog/2011/12/social-digital-mobile-south-asia/.

Kietzmann, J. H. (2012). Unpacking the social media phenomenon towards a research agenda. 109-119.

P, E. (2013). Pakistan-Telcecom_Mobile_Broadband-and-Forecasts. Retrieved from Executive Summary: www.budde.com.au?Research?Pakistan-Telecoms_Mobile_Broadbandand-Forecasts.html

R., C. H. (n.d.). Social Media in Higher Education: A literature review and research directions from the Selected Works.

Rachel. (2012). The Use of Social Media in Higher Education for Marketing and Communications: A Guide for Professionals in Higher Education.

Reuben, R. (2011). Social Media in Higher Education; Data Analysis of Relevant Studies. USA: National School Board Association.

Ricardo, S. (2011). Pros and Cons of Facebook. Retrieved from http://senioritisricardo.blogspot.com/2011_03_01_archive.html: http://senioritisricardo.blogspot.com/2011_03_01_archive.html

Rideout VJ, F. U. (2010: Report No.:8010). Generation M2: Media in the Lives of 8- to 18Year-Olds. Menlo Park, CA: Kaiser Family Foundation.

Russell, J. (2011). Increasing importance of social media in education. Hong Kong: Polytechnic University . 
S., K. (2011-12). Internet Population in South Asia. Retrieved June 30, 2013, from Social, Digital and Mobile in South Asia: wearesocialnet.net/blog/2011/12

S.Young, K. (Fall 1998). Cyber Psychology and Behavior. Retrieved from http://online.liebertpub.com/doi/abs/10.1089/cpb.1998.1.237.

Sanou, B. (2011). Measuring the Information Society. Retrieved from International Telecommunication Union: www.itu.int/net/pressoffice/backgrounders/general/pdf/5.pdf

(2011). Social Media in Higher Education; Data Analysis of Relevant Studies . National School Board Association, USA.

(2012). Social Media in Higher Education; Data Analysis of Relevant Studies . University of Massachusetts Dartmouth Center for Marketing Research,.

(2011). Social Media in Higher Education; Data Analysis of Relevant Studies. National School Board Association, USA.

Social Media Strategy for Higher Education. (2012, May). Retrieved from http://www.slideshare.net/Petersons/social-media-for-educational-institutions-increasestudent-retention-and-enrolltostarts-with-targeted-social-media

Teller, S. (2013). Pakistan Market Trends 2013: Online, Mobile, Social - Things Are About To Take Off. http://ansr.io/blog/pakistan-market-trends-2013-online-mobile-social/.

Ten (10) Ways Universities Share Information Using Social Media. (2009, 5 17). Retrieved from http://mashable.com/2009/07/15/social-media-public-affairs/

World Economic Forum. The Financial Development Report 2012. (2012). Retrieved from www.weforum.org/reports/financial-development-report-

20121http://www.pta.gov.pk/index.php?option=com_content\&view=article\&id=269\&Itemid $=599$

\section{Other Web Sources:}

2) IBA Website www.iba.edu.pk

2s IBA Social Media Strategy Paper and Action Plan by Dr Zaheeruddin Asif and Social Media Committee www.iba.edu.pk

2 Minutes of 214th Meeting of the Executive Committee of IBA Held on Monday, August 6, 2012; IBA Karachi Portal http://iba/ Facebook Pages

Institute of Business Administrationhttp://www.facebook.com/ibakarachicity

2 www.facebook.com/ibakarachicity?sk=page insights

2s Lahore University of Management Scienceshttp://www.facebook.com/LifeAtLUMS 
https://ir.iba.edu.pk/businessreview/vol9/iss2/12

DOI: https://doi.org/10.54784/1990-6587.1278

Business Review - Volume 9 Number 2

25 Karachi School of Business and

Leadershiphttps://www.facebook.com/KSBLPakistan

2) Stanford http://www.facebook.com/stanford

Twitter Pages

2) IBA http://twitter.com/ibakarachi http://www.youtube.com/ibaedudotpk

25 LUMS https://twitter.com/lifeatlums http://www.youtube.com/lifeatlums

26 KSBL https://twitter.com/ksblpakistan KSBL http://www.youtube.com/user/ksblpakistan

es Stanford https://twitter.com/stanford Stanford http://www.youtube.com/stanford
YouTube Channels

IBA

LUMS

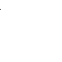

"There remains, nevertheless, the cheerful possibility that we actually know less about the Science of Man than we do of the less difficult sciences of matter and that we may, just in time, learn more. Perhaps Hamlet was nearer right than Pavlov. Perhaps the exclamation "How life a god!" is actually more appropriate than "How like a dog! How like a rat! How like a machine!"

Joseph Wood Krutch, The Measure of Man, p. 32 